\title{
Benign serous cystadenoma presenting with cough and back pain
}

\author{
Madeleine Rudolph BHSc, Jessie Peng MD, Peter E. Wu MD MSc
}

Cite as: CMAJ 2021 August 23;193:E1304. doi: 10.1503/cmaj.202850

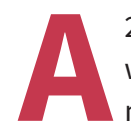

27-year-old woman presented to the emergency department with a 1-week history of dry cough, preceded by 1 month of nontraumatic back pain. Her heart rate was 110 beats/min, and her other vital signs, cardiac examination and respiratory examination were normal. She had an elevated body mass index $\left(55 \mathrm{~kg} / \mathrm{m}^{2}\right)$ with no palpable masses on abdominal examination. Complete blood count showed a hemoglobin level of 86 (normal 120-160) g/L, mean corpuscular volume of 85 (normal 80-95) fL, red cell distribution width (coefficient of variation) of $15.7 \%$ (normal $11.5 \%-14.8 \%$ ), an eosinophil count of 0.6 (normal $0.04-0.4$ ) $\times 10^{9} / \mathrm{L}$ and a platelet count of 801 (normal $150-400$ ) x 10\% $/$ L. Test results for human chorionic gonadotropin ( $\beta$-HCG) were negative. An extensive workup for autoimmune disease, connective tissue disease, infection and drug exposure was negative. To investigate the patient's cough, we performed a computed tomography (CT) scan of her thorax that showed nonspecific ground glass opacities and atelectasis, as well as the superior aspect of an ill-defined, intra-abdominal lesion. A CT scan of her abdomen (Figure 1) showed a large, nonenhancing cystic mass, originating from the right ovary with consequent torsion. A test of the patient's cancer antigen 125 (CA-125) showed a level of 355 (normal $\leq 34$ ) U/mL.

The patient underwent an urgent partial oophorectomy and salpingectomy. Our surgeons removed the cystic mass, and drained $11 \mathrm{~L}$ of blood-tinged fluid from the cyst. Pathology of the mass was negative for malignancy. We diagnosed benign serous cystadenoma with secondary infarction and hemorrhage due to torsion. After surgery, the patient's cough, back pain, eosinophilia, anemia and thrombocytosis, presumed to be reactive, resolved.

Serous cystadenomas account for about $25 \%$ of benign ovarian neoplasms in patients of reproductive age. ${ }^{1,2}$ The growth is insidious, and diagnosis can be difficult because patients are often asymptomatic. ${ }^{3}$ Patients with serous cystadenomas often become symptomatic only if lesions undergo torsion or exert a mass effect due to their size. This was the case in our patient whose cough and back pain prompted her to seek medical attention, which led to a definitive diagnosis and treatment.

\section{References}

1. Glanc P, Benacerraf B, Bourne T, et al. First international consensus report on adnexal masses: management recommendations. J Ultrasound Med 2017;36:849-63.

2. Froyman W, Landolfo C, De Cock B, et al. Risk of complications in patients with conservatively managed ovarian tumours (IOTA5): a 2-year interim analysis of a multicentre, prospective, cohort study. Lancet Oncol 2019;20:448-58.

3. Salvador S, Scott S, Glanc P, et al. Guideline no. 403: initial investigation and management of adnexal masses. J Obstet Gynaecol Can 2020;42:1021-9.e3.

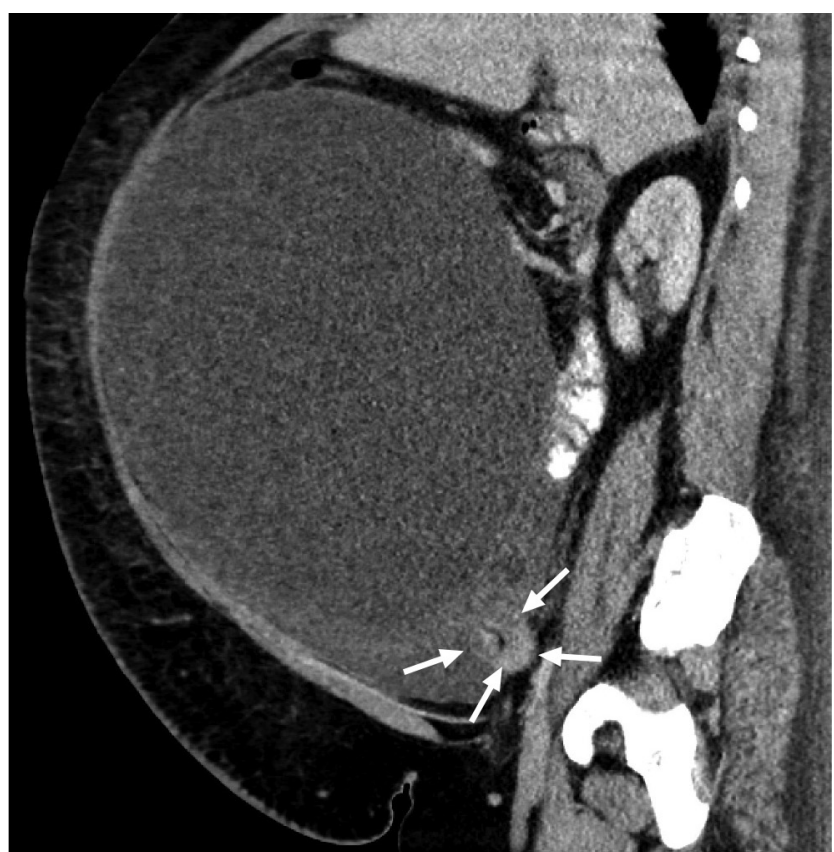

Figure 1: Contrast-enhanced, abdominal computed tomography scan of a 27-year-old woman with a serous cystadenoma. Sagittal image shows a $34 \times 32.3 \times 25.7 \mathrm{~cm}$ mass and swirling of the right ovarian pedicle (arrows), as well as mass effect and superior displacement of the left lobe of the liver.

Competing interests: None declared.

This article has been peer reviewed.

The authors have obtained patient consent.

Affiliations: Faculty of Medicine (Rudolph) and Department of Medicine (Peng, Wu), University of Toronto, Toronto, Ont.

Content licence: This is an Open Access article distributed in accordance with the terms of the Creative Commons Attribution (CC BY-NC-ND 4.0) licence, which permits use, distribution and reproduction in any medium, provided that the original publication is properly cited, the use is noncommercial (i.e., research or educational use), and no modifications or adaptations are made. See: https://creativecommons.org/licenses/by-nc-nd/4.0/

Acknowledgements: The authors thank Dr. Marcus Bernardini for feedback and review of this manuscript, and Dr. Luis Guimaraes for review and editing of the radiologic images, as well as to both for their care of this patient.

Correspondence to: Madeleine Rudolph, m.rudolph@mail.utoronto.ca 